\title{
Impact of asthma severity as risk factor to future exacerbations in patients admitted for asthma exacerbation
}

\author{
Narongwit Nakwan \\ Division of Pulmonology, Department of Medicine, Hat Yai Medical Education Center, Hat Yai Hospital, Songkhla, Thailand
}

\begin{abstract}
Background: To investigate the impact of disease severity on exacerbation patterns and identify its potential as a risk factor for future exacerbations in patients admitted for asthma exacerbations.

Methods: We analyzed frequency and time to next exacerbation over a period of three years in 532 patients admitted for exacerbation. Disease severity was selected as a potential risk factor for the events. Kaplan-Meier analysis was used to identify the probability of future exacerbations. A Cox-proportional hazards model was used to assess independent relative risks.

Results: Out of 532 patients analyzed, the frequency of exacerbations rose as the severity of the asthma increased. The exacerbation rates in the following year were 1.66 per person for patients with mild asthma and 3.98 for patients with severe asthma. The median time to the next exacerbation in patients with mild asthma was 61.4 weeks (95\% CI, 40.182.6) compared to 15.0 weeks $(95 \% \mathrm{CI}, 11.3-18.6)$ in patients with severe asthma $(\mathrm{p}<0.001)$. Multivariate analysis showed that asthma severity (severe vs mild asthma, HR=1.42, 95\% CI, 1.07-1.89), a history of 1-2 exacerbations $(\mathrm{HR}=1.95,95 \% \mathrm{CI}, 1.45-2.63)$ or $>2$ exacerbations $(\mathrm{HR}=2.32,95 \% \mathrm{CI}, 1.56-3.44)$ in the previous 12 months, and a high number of comorbidities ( $\geq 5$ vs none, $\mathrm{HR}=2.5,95 \% \mathrm{CI}, 1.41-4.45$ ) were independent predictors of the probability of future exacerbations.

Conclusion: Asthma severity is a strong independent risk factor for future exacerbations, and exacerbation rates also become more frequent as the severity of the asthma increases. These findings help in better understanding of the natural course of exacerbations across the spectrum of asthma disease severity.
\end{abstract}

Key words: asthma severity; asthmatic exacerbation; hospitalization.

Correspondence: Narongwit Nakwan, M.D, Division of Pulmonology, Department of Medicine, Hat Yai Medical Education Center, Hat Yai Hospital, Songkhla 90110, Thailand.

Tel. +66.8.18984566 - Fax: +66.7.4261093. E-mail: naronak@hotmail.com

Contributions: The author had full access to all of the data in the study and takes responsibility for the integrity of the data, accuracy of the data analysis, study design, data analysis and interpretation, and the writing of the manuscript.

Conflict of interest: The author declares no conflict of interest.

Funding: The author received no financial support for the research, authorship, and/or publication of this article.

Availability of data and materials: The data set used in the study is available from the author upon reasonable request.

Ethics approval: The protocol of the study was approved by the Institutional Review Board of Hat Yai Hospital.

Consent for publication: Not applicable. 


\section{Introduction}

Asthma is a highly prevalent chronic respiratory disease that according to a recent study, affects over more than 239 million people worldwide [1]. Although the international asthma guidelines are updated on a yearly basis to include newly available innovative inhaler medications [2,3], asthma exacerbations are still a problem that not only remains but is following an upward trend [4]. Many potentially modifiable factors have been demonstrated as risk factors for exacerbation, including having uncontrolled asthma symptoms [5], a history of near-fatal asthma [6], a history of previous exacerbations in the previous 12 months [7], comorbidities [8], poor lung function [9] and exposure to noxious particles or allergens [9]. However, the disease severity of asthma has not been exclusively investigated as a potential risk factor for exacerbations. Recent research has demonstrated how the natural history of asthma is frequently punctuated by exacerbations across patients with asthma of varying severities, despite good asthma control [10]. Other studies have found that the frequency of exacerbation becomes more frequent as the severity of the asthma increases [11-17].

Therefore, it is important to note that asthma severity may be a major driver of exacerbations and implies a causal relationship between asthma phenotypes and asthma control. The author suggests the hypothesis that asthma severity may be a potential risk factor for future exacerbations and that exacerbation patterns may be impacted by varying levels of asthma severity. Therefore, this study was conducted to gain a better understanding of how varying degrees of asthma severity impact future exacerbations, especially among patients admitted for asthma exacerbation.

\section{Methods}

\section{Study design}

The study was a retrospective cohort study conducted between October 2016 and September 2019. The protocol was approved by the Institutional Review Board of Hat Yai Hospital. The study used medical inpatient charts as the source of data. These charts included details of each patient's first admission for asthmatic exacerbation based on the principal diagnosis by the International Statistical Classification of Diseases and Related Health Problems 10 (code J45.0-J45.9 and J46) in the discharge summary. All admission charts were externally audited and diagnoses for asthmatic exacerbations were confirmed by a pulmonologist. The need for individual consent was waived by the committee due to no direct contact being made with the patients. The study sample included 532 patients, whose baseline characteristics, comorbidities, and asthma exacerbation characteristics following hospitalization were recorded.

\section{Patient population}

The study population consisted of patients who met the following criteria: diagnosed with asthma and asthmatic exacerbation defined according to the standard of the Global Initiative for Asthma (GINA) (2), aged $>18$ years, and a history of having good asthma control as assessed by an asthma control test (score $>23$ ) in the preceding 12 weeks. Patients who died during their hospitalization were excluded. Moreover, they were also excluded from the study if they were pregnant; had a history of lung cancer, tuberculosis, lung fibrosis, previous lung surgery, or pulmonary edema; or had incomplete clinical data on their asthma exacerbation events.
Each individual patient was recorded following the index event, and all following exacerbation admissions during the study period after discharge were recorded as well. For patients with multiple visits for asthmatic exacerbations beyond the index event, the first event only was incorporated in the survival analysis.

\section{Data collection}

The demographic and clinical data associated with the investigation and treatment of each admission were extracted from medical records including age, gender, smoking status, comorbidities, asthma severity, treatment steps, and number of exacerbations in the previous 12 months. The clinical parameters collected during admission included whether intubation was required, blood eosinophil count (BEC), complications, duration of hospital stay and last treatment steps before hospital admission. The clinical parameters following discharge were the number of asthma exacerbations within 12 months of discharge and the length of time to the first asthma exacerbation. Exacerbations following discharge were defined as events that required an emergency room visit leading to the use of systemic glucocorticosteroids or leading to hospitalization. Level of asthma severity was classified into mild, moderate and severe based on the intensity of the treatment required to achieve good asthma control [18]. The treatment steps were defined according to GINA stepwise management [2].

\section{Statistical analysis}

All statistical analyses were conducted using SPSS Statistics version 23 for Windows. Continuous or ordinal values are presented as mean $\pm \mathrm{SD}$ and were analyzed using unpaired t-test. Categorical values are presented as numbers with proportions and were analyzed using Chi-square test. The log-rank test was used to compare time to the first exacerbation after discharge at 3 years, and the Kaplan-Meier method was used to build a probability of having future asthma exacerbation curve. We used Cox proportional hazards regression to calculate unadjusted and multivariateadjusted hazard ratios for future exacerbations for each factor; $\mathrm{p}<0.05$ in all statistical analyses was considered to indicate statistical significance. The study built sequential models adding 1 risk factor group at a time to the model to identify significant variables until all variables were assessed for inclusion. A conservative value for statistical significance was required for inclusion in the final model $(\mathrm{p} \leq 0.001)$.

\section{Results}

\section{Demographic characteristics}

A total of 532 patients admitted for asthma exacerbation were included in the study and their details are summarized in Table 1. The mean age was $44.1 \pm 11.6$ years, with a majority of them being women $(71.8 \%)$. There were $93(17.5 \%)$ patients with a history of smoking and the mean cumulative smoking period was $18.9 \pm 24.0$ pack/years. Within the previous 12 months, 294 (55.3\%) patients had an experience of at least one exacerbation and the mean number of asthmatic exacerbations was $2.3 \pm 3.0$. The mean length of hospital stay was $2.3 \pm 3.0$ days. A total of $87(16.4 \%)$ patients had been intubated. The mean BEC was $327.7 \pm 402.1$ cells $/ \mathrm{mm}^{3}$. In terms of their asthma treatment, $252(47.3 \%)$ patients were using as-needed SABA.

\section{Baseline characteristic according to asthma severity}

Among these 532 patients, 271 (50.9\%) had mild asthma, 79 
(14.8\%) had moderate asthma, and $182(32.3 \%)$ had severe asthma, with all characteristics shown in Table 1 . The patients with mild asthma had experienced fewer asthmatic exacerbations in the previous 12 months before their present hospital admission $(35.6 \%$ vs $79.2 \%$ in severe asthma), while the number of previous exacerbations during the preceding 12 months was also lower for those with mild asthma ( 0.63 per person) than for patients with severe asthma (6.45 per person). Length of hospital stay showed no significant differences among the different groups. Surprisingly, patients with mild asthma had a higher proportion of complications requiring intubation $(21.4 \%$ vs $10.4 \%$ for those with severe asth$\mathrm{ma})$ and the highest BEC $\left(408.9 \pm 399.8\right.$ cells $/ \mathrm{mm}^{3}$ vs $205.9 \pm 141.3$ cells $/ \mathrm{mm}^{3}$ for those with severe asthma).

\section{Future asthma exacerbations following discharge}

During the follow up period, the clinical data on future exacerbation events across all disease severity levels of asthma are summarized in Table 2. A total of 408 (76.6\%) patients experienced one or more subsequent exacerbation within the following 12 months, whereas 124 (23.4\%) did not experience an exacerbation. As the level of asthma severity increased, the exacerbations were found to be more frequent and more severe. In the first year after hospitalization, the exacerbation rates were 1.66 per person for patients with mild asthma, 2.42 for those with moderate asthma, and 3.98 for those with severe asthma. Patients with severe asthma had significantly higher rates of asthma exacerbations leading to either emergency room treatment or hospitalization than those with mild asthma. The median time to the first exacerbation after the original hospitalization was significantly different among the groups of different asthma severity ( $\mathrm{p}$ for log rank test $<0.001$ ) (Figure 1). In the patients with mild asthma, it was 61.4 weeks (95\% CI, 40.1-82.6), while for those with moderate asthma, it was 25.8 weeks (95\% CI, 13.2-38.4), and for those with severe asthma, it was 15 weeks $(95 \%$ CI, 11.3-18.6). Furthermore, having a high number of previous exacerbations within the past 12 months, male sex, and having a high number of comorbidity diseases were significantly associated with the time to the first future exacerbation (Figure 1).

\section{Risk factors for future exacerbations in patients admit- ted for asthma exacerbation}

From the Cox proportional hazards regression analysis, severe asthma was found to be associated with a $42 \%$ increase in the risk of future asthma exacerbations (Table 3). Furthermore, the following factors were also found to be related to increased risk: a history or number ( $>2$ visits and 1-2 visits $v s$ never) of previous exacerbations in the last 12 months and a high number of comorbidity diseases. According to sequential modelling, patients with severe

Table 1. Baseline demographics and characteristics of the study population

\begin{tabular}{|c|c|c|c|c|c|}
\hline Characteristic & $\begin{array}{l}\text { All subjects } \\
\quad(n=532)\end{array}$ & $\begin{array}{l}\text { Mild asthma } \\
\qquad(\mathrm{n}=271)\end{array}$ & $\begin{array}{l}\text { Moderate asthma } \\
(\mathrm{n}=79)\end{array}$ & $\begin{array}{l}\text { Severe asthma } \\
\quad(n=182)\end{array}$ & $\mathbf{p}$ \\
\hline Age, years \pm SD & $44.1 \pm 11.6$ & $40.1 \pm 11.3$ & $55.6 \pm 12.2$ & $46.1 \pm 4.7$ & 0.055 \\
\hline $\begin{array}{l}\text { Gender, n (\%) } \\
\text { Male } \\
\text { Female }\end{array}$ & $\begin{array}{l}150(28.2 \%) \\
382(71.8 \%)\end{array}$ & $\begin{array}{c}79(29.2 \%) \\
192(70.8 \%)\end{array}$ & $\begin{array}{l}22(27.8 \%) \\
57(72.2 \%)\end{array}$ & $\begin{array}{c}49(6.9 \%) \\
133(73.1 \%)\end{array}$ & 0.873 \\
\hline $\begin{array}{l}\text { Smoking status, } \mathrm{n}=325(\%) \\
\text { Current } \\
\text { Former } \\
\text { Never } \\
\text { NA }\end{array}$ & $\begin{array}{c}57(10.7 \%) \\
36(6.8 \%) \\
265(49.8 \%) \\
164(32.7 \%)\end{array}$ & $\begin{array}{c}43(15.9 \%) \\
11(4.1 \%) \\
143(52.8 \%) \\
74(27.3 \%\end{array}$ & $\begin{array}{c}9(11.4 \%) \\
5(6.0 \%) \\
33(41.8 \%) \\
32(40.5 \%)\end{array}$ & $\begin{array}{c}5(2.7 \%) \\
20(11.0 \%) \\
89(48.9 \%) \\
68(37.4 \%)\end{array}$ & $<0.001$ \\
\hline Smoking, Pack/years & $18.9 \pm 24.0$ & $9.6 \pm 12.6$ & $8.4 \pm 7.0$ & $40.6 \pm 32.6$ & $<0.001$ \\
\hline $\begin{array}{l}\text { Comorbidities, n (\%) } \\
\text { No } \\
1-2 \\
3-4 \\
15\end{array}$ & $\begin{array}{c}283(53.2 \%) \\
193(36.3 \%) \\
41(7.7 \%) \\
15(2.8 \%)\end{array}$ & $\begin{array}{c}177(65.3 \%) \\
84(31 \%) \\
10(3.67 \% \\
0\end{array}$ & $\begin{array}{c}37(46.8 \%) \\
32(40.5 \%) \\
9(11.4 \%) \\
1(1.3 \%)\end{array}$ & $\begin{array}{c}69(37.9 \%) \\
77(42.3 \%) \\
212(12.1 \%) \\
14(7.7 \%)\end{array}$ & $<0.001$ \\
\hline Previous exacerbation(s) in last 12 months, $\mathrm{n}(\%)$ & $294(55.3 \%)$ & $97(35.6 \%)$ & $53(67.1 \%)$ & $144(79.2 \%)$ & $<0.001$ \\
\hline Number of previous exacerbations in last 12 months, times \pm SD & $2.3 \pm 3.0$ & $0.63 \pm 0.97$ & $4.0 \pm 1.73$ & $6.45 \pm 2.66$ & $<0.001$ \\
\hline Hospital stay, days \pm SD & $3.2 \pm 2.9$ & $3.7 \pm 5.1$ & $3.0 \pm 2.7$ & $4.1 \pm 4.7$ & 0.258 \\
\hline Intubation, $\mathrm{n}(\%)$ & $87(16.4 \%)$ & $58(21.4 \%)$ & $10(12.7 \%)$ & $19(10.4 \%)$ & 0.005 \\
\hline $\mathrm{BEC}$, cells $/ \mathrm{mm}^{3}$ & $327.7 \pm 402.1$ & $408.9 \pm 399.8$ & $199.2 \pm 345.0$ & $205.9 \pm 141.3$ & 0.353 \\
\hline $\begin{array}{l}\text { Asthma medications, n (\%) } \\
\text { As-need SABA } \\
\text { Low dose ICS } \\
\text { Medium dose ICS } \\
\text { Low dose ICS/LABA } \\
\text { Medium dose ICS/LABA } \\
\text { High dose ICS/LABA } \\
\text { LAMA } \\
\text { Montelukast } \\
\text { Xanthine derivatives } \\
\text { OCS }\end{array}$ & $\begin{array}{c}252(47.3 \%) \\
19(3.5 \%) \\
17(3.2 \%) \\
62(11.6 \%) \\
159(29.8 \%) \\
23(4.3 \%) \\
17(3.2 \%) \\
131(24.6 \%) \\
107(20.1 \%) \\
7(1.3 \%)\end{array}$ & $\begin{array}{c}252(92.9 \%) \\
19(7.0 \%) \\
0 \\
0 \\
0 \\
0 \\
0 \\
10(3.7 \%) \\
22(8.1 \%) \\
2(0.7 \%)\end{array}$ & $\begin{array}{c}0 \\
0 \\
17(21.5 \%) \\
62(78.5 \%) \\
0 \\
0 \\
1(1.2 \%) \\
19(24.0 \%) \\
10(12.6 \%) \\
3(3.7 \%)\end{array}$ & $\begin{array}{c}0 \\
0 \\
0 \\
0 \\
159(87.3 \%) \\
23(12.6 \%) \\
16(8.8 \%) \\
102(56.0 \%) \\
75(41.2 \%) \\
2(1.1 \%)\end{array}$ & $\begin{array}{c}<0.001 \\
<0.001 \\
<0.001 \\
0.043\end{array}$ \\
\hline
\end{tabular}

Values are shown as mean \pm SD or number (\%); NA, not available; BEC, blood eosinophil count; SABA, short-acting beta-2 agonist; ICS, inhaled corticosteroid; LABA, long-acting beta-2 agonist; LAMA, long-acting anti-muscarinic antagonist; OCS, oral corticosteroid. 
asthma were at increased risk of future exacerbations after adjustment for age, number of previous exacerbations in the previous 12 months, comorbidities, and BEC, even in the final model (Table 4).

\section{Discussion}

This is the first study to identify the severity of asthma as a strong independent risk factor for future exacerbations in patients admitted for asthma exacerbation. The risk of future exacerbations becomes higher as the severity of the asthma increases. Severe asthma has a $42 \%$ higher risk of future exacerbations compared to mild asthma. Additionally, an increase in the severity of asthma also influences future exacerbation patterns. In those with severe asthma, there is a higher frequency of exacerbations within the first
12 months and a greater probability of developing those events in shorter time intervals compared to those with mild asthma. Also, recent exacerbations still remain a strong, reliable independent risk factor for future exacerbations, with the frequency of recent exacerbations also increasing as the severity of the asthma increases. A high number of comorbidity diseases is also associated with future risk of exacerbations after the variables are adjusted. Although the level of BEC has a relation to asthma-related outcomes [19], this factor could not be considered a predictor of future risk of exacerbations after adjustment. The robust data we have provided from this study shows that the severity of asthma in patients admitted for asthma exacerbation can predict future exacerbations and exacerbation patterns, including the frequency of exacerbations and the length of time to the first future exacerbation following hospitalization. These findings can help to provide a deeper understanding
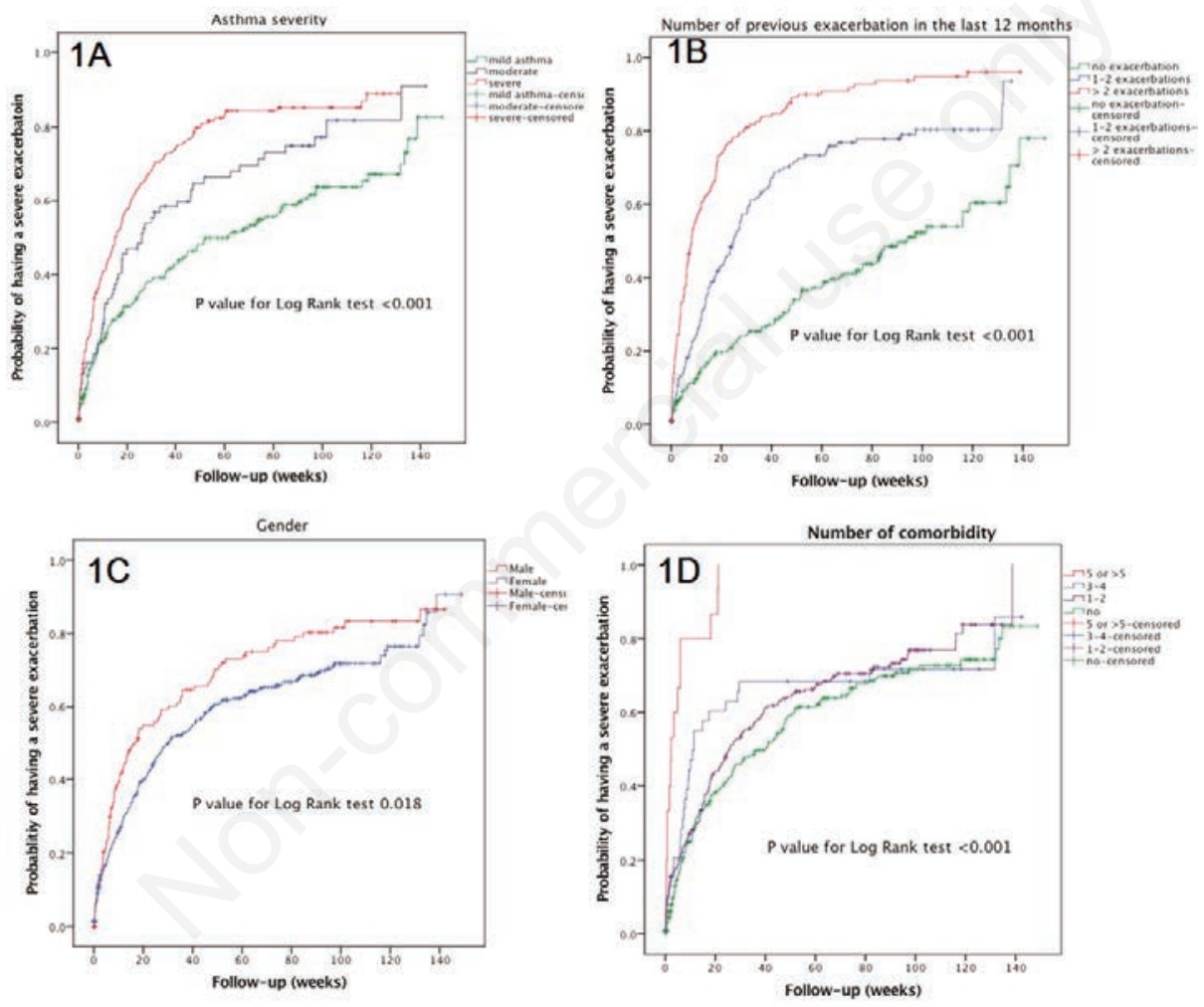

Figure 1. Kaplan-Meier curves indicating probability of having future severe exacerbations following discharge classified by a) asthma severity, b) number of exacerbations in the previous 12 months, c) gender, and d) number of comorbidities

Table 2. Future severe asthmatic exacerbations following discharge.

\begin{tabular}{|c|c|c|c|c|c|}
\hline Outcome & $\begin{array}{l}\text { All subjects } \\
(\mathrm{n}=532)\end{array}$ & $\begin{array}{l}\text { Mild asthma } \\
(\mathrm{n}=271)\end{array}$ & $\begin{array}{c}\text { Moderate asthma } \\
(\mathrm{n}=79)\end{array}$ & $\begin{array}{l}\text { Severe asthm } 2 \\
(n=182)\end{array}$ & a p \\
\hline Future exacerbation within 12 months, $n(\%)$ & $408(76.7 \%)$ & $188(69.4 \%)$ & $61(77.2 \%)$ & $159(87.4 \%)$ & $<0.001$ \\
\hline Severe exacerbation(s) within 12 months, visits \pm SD & $2.70 \pm 3.35$ & $1.66 \pm 2.69$ & $2.42 \pm 3.26$ & $3.98 \pm 3.62$ & $<0.001$ \\
\hline Severe exacerbation leading to emergency room treatment within 12 months, visits $\pm S D$ & D $1.66 \pm 2.41$ & $1.01 \pm 1.88$ & $1.42 \pm 2.29$ & $2.48 \pm 2.75$ & 0.006 \\
\hline Severe exacerbation leading to hospitalization within 12 months, visits \pm SD & $1.03 \pm 1.96$ & $0.61 \pm 1.59$ & $0.80 \pm 1.58$ & $1.60 \pm 2.32$ & 0.002 \\
\hline Median time to severe exacerbation, weeks $(95 \% \mathrm{CI})$ & $27.0(20.7-33.2)$ & $61.4(40.1-82.6)$ & $25.8(13.2-38.4)$ & $15.0(11.3-18.6)$ & $<0.001$ \\
\hline
\end{tabular}

Values are shown as mean \pm SD. 
of the linkage and natural course of asthma between severity of asthma and asthma exacerbations.

In the patients admitted for asthma exacerbation that we examined for this study, the major determinant for the future risk of exacerbation was the severity of their asthma $(\mathrm{HR}=1.42 ; 95 \% \mathrm{CI}$ 1.07-1.89). It is worth noting here that even though the asthma of all participants was considered to be well-controlled based on their responses to asthma questionnaires, they still experienced asthma exacerbations. Our results suggest that asthma severity may be a strong causal factor in future asthma exacerbations. The new concepts on the severity of asthma refer to the intensity of the treatment required to achieve control, and asthma control is defined by the complete absence or minimal presence of symptoms or the lack of a requirement for emergency treatment [18]. Nevertheless, there is the possibility of some discordance in the relationship between the severity of asthma and asthma control. The distinct asthma phenotypes can explain this finding. The heterogeneity of the underlying process of asthma affects the natural history and treatment response, leading to the distinct features of the asthma phenotypes [20]. However, the varying disease activity in individual patients may influence different asthma outcomes, such as by manipulating the asthma severity and asthma control [18]. Several different studies have demonstrated the overall frequency of asthma exacerbation among patients with varying levels of asthma severity, with up to a $22 \%$ frequency found in patients with mild asthma [21,22], while in those with severe asthma, this rate increased to $48 \%$ [23]. According to our results, we also found that increased severity of asthma was associated with increased exacerbation frequency, in the periods of either the preceding year or the following year. Moreover, our data suggest that increased severity of asthma also makes a patient susceptible to a shorter time to their first subsequent exacerbation following discharge. Among the patients who had severe asthma, the length of time to the first subsequent exacerbation was only 15 weeks - an important observation considering that such patients must be followed-up closely after hospitalization. Thus, even when it is controlled, severe asthma is still considered a severe form of asthma due to the future risk of serious adverse events it presents [24] and the effects of the asthma phenotype and the varying disease activity in individual patients on the asthma severity [20]. Patients who used either asneeded SABA as their only treatment or daily low-dose inhaled corticosteroid were classified as having mild asthma; nevertheless, the proportion of patients with mild asthma who were admitted for asthma exacerbation was higher than the proportion of patients with severe asthma. Our study concerned asthma exacerbations, which are burdensome to patients with mild asthma. Recent systematic reviews support the understanding that the burden of exacerbations in patients with mild asthma is still considered problematic in clinical epidemiology [22]. In our study, the level of BEC in patients with mild asthma was rather elevated compared to those with severe asthma, which could indicate that treating non-suppressible airway inflammation with only SABA means that such patients are being under-treated or not receiving the proper medications, even though they are achieving asthma control. According to the latest guidelines, the use of SABA alone is no longer recommended, and now the concomitant use of an inhaled steroid is suggested, even in treatment step 1 [2].

In the multivariate analysis of data for the entire cohort, a history of previous asthma exacerbations was associated with future exacerbations in patients admitted for asthma exacerbations $(\mathrm{HR}=$ 2.32; $95 \%$ CI 1.56-3.44 for $>2$ previous exacerbations and $\mathrm{HR}=$ $1.95 ; 95 \%$ CI $1.45-2.36$ for $1-2$ previous exacerbations). This rela-

Table 3. Significant risk factors for future exacerbations following discharge in multivariate Cox regression analysis.

\begin{tabular}{|c|c|c|}
\hline Clinical predictor & HR (95\% CI) & $\mathbf{p}$ \\
\hline Age & $0.99(0.98-0.99)$ & 0.010 \\
\hline Male gender & $1.17(0.90-1.53)$ & 0.236 \\
\hline $\begin{array}{l}\text { Number of exacerbations in previous } 12 \text { months } \\
1-2 \text { visits } v s \text { none } \\
>2 \text { visits } v \text { s none }\end{array}$ & $\begin{array}{l}1.10(1.05-1.14) \\
1.95(1.45-2.63) \\
2.32(1.56-3.44)\end{array}$ & $\begin{array}{l}<0.001 \\
<0.001 \\
<0.001\end{array}$ \\
\hline $\begin{array}{l}\text { Number of comorbidities } \\
\geq 5 \text { us none }\end{array}$ & $2.5(1.41-4.45)$ & 0.002 \\
\hline $\begin{array}{l}\text { Asthma severity } \\
\text { Moderate } v s \text { mild asthma } \\
\text { Severe } v s \text { mild asthma } \\
\text { Intubation }\end{array}$ & $\begin{array}{l}1.11(0.79-1.55) \\
1.42(1.07-1.89) \\
0.89(0.61-1.28)\end{array}$ & $\begin{array}{l}0.531 \\
0.017 \\
0.535\end{array}$ \\
\hline
\end{tabular}

$\mathrm{Cl}$, confidence interval; HR, hazard ratio.

Table 4. Effects of multivariable adjustment on the association of disease severity of asthma with future exacerbations.

\begin{tabular}{lcccccc} 
Model & Mild asthma & Moderate asthma & p & Severe asthma & p \\
1 & 1.00 & 1.63 & 0.003 & 2.51 & $<0.001^{*}$ \\
2 & 1.00 & 1.31 & 0.098 & 1.58 & $0.001^{*}$ \\
\hline 3 & 1.00 & 1.52 & 0.009 & 2.07 & 2.22 & $<0.001^{*}$ \\
4 & 1.00 & 1.74 & $0.001 \dagger$ & 1.70 & $<0.001^{*}$ \\
\hline 5 & 1.00 & 1.49 & 0.019 & $<.001^{*}$
\end{tabular}

Model 1 is adjusted for age; model 2 is additionally adjusted for number of exacerbations in previous 12 months; model 3, comorbidities; model 4, blood eosinophils; model 5 is the full model. Data are expressed as hazard ratios; ${ }^{*} \mathrm{p} \leq 0.001$ indicates significance 
tionship that was observed in the present study has been noted previously [7,25-27]. In addition, a relationship between a high number of comorbidities ( $\mathrm{HR}=2.5 ; 95 \% \mathrm{CI} 1.41-4.45)$ and future exacerbations was observed in our study. This would indicate that this variable should be recognized as an integral part of the core management of asthma because of its potential for influencing the clinical expression and severity of asthma [8]. However, no previous reports have supported the impact of the treatment of comorbidities on asthma severity and long-term clinical outcomes.

The limitations of our study are mainly due to its structure as a unicentric retrospective study, the findings of which may not have external validity. Our database did not include data on spirometry and other specific biomarkers, including fractional exhaled nitric oxide and sputum eosinophil measurements. In addition, as baseline asthma characteristics such as smoking status and comorbidity were not well defined during the data collection process, they may be under-reported in the clinical charts. Another important consideration is that the precipitating factors of exacerbation were not clearly identified, and such missing information might have confounded the clinical or laboratory outcomes. Moreover, our study covered only two years, which may have been too short a period to gather enough data or to recruit a large enough group of patients to arrive at significant conclusions.

In conclusion, our study confirms the observation that the probability of having future exacerbations following asthma-related hospitalization increases in frequency as the severity of asthma increases and shows that a history of exacerbations and comorbidities are also important factors in the likelihood of having future exacerbations. These findings support the hypothesis that the severity of asthma can predict exacerbations and may be a driver of these adverse events.

\section{Acknowledgements}

The author would like to thank John Wangwanitkul and Patterson David Leslie for their supports in academic proofreading.

\section{References}

1. GBD 2016 Disease and Injury Incidence and Prevalence Collaborators. Global, regional, and national incidence, prevalence, and years lived with disability for 328 diseases and injuries for 195 countries, 1990-2016: a systematic analysis for the Global Burden of Disease Study 2016. Lancet 2017;390:1211-59.

2. Global Initiative for Asthma (GINA). Global Strategy for Asthma Management and Prevention, Updated 2020. Accessed: November 1, 2020. Available from: http://www.ginasthma.org

3. British Thoracic Society. BTS/SIGN British Guideline on the Management of Asthma updated 2019. Accessed: December 1, 2019. Available from: https://brit-thoracic.org.uk/qualityimprovement/guidelines/asthma/

4. Schatz M, Meckley LM, Kim M, Stockwell BT, Castro M. Asthma exacerbation rates in adults are unchanged over a 5year period despite high-intensity therapy. Allergy Clin Immunol Pract 2014;2:570-4.

5. McCoy K, Shade DM, Irvin CG, Mastronarde JG, Hanania NA, Castro M, et al. Predicting episodes of poor asthma control in treated patients with asthma. J Allergy Clin Immunol 2006;118:1226-33.

6. Turner MO, Noertjojo K, Vedal S, Bai T, Crump S, FitzGerald JM. Risk factors for near-fatal asthma. A case-control study in hospitalized patients with asthma. Am J Respir Crit Care Med 1998;157:1804-9.

7. Miller MK, Lee JH, Miller DP, Wenzel SE. Recent asthma exacerbations: a key predictor of future exacerbations. Respir Med 2007;101:481-9.

8. Boulet LP. Influence of comorbid condition on asthma. Eur Respir J 2009;33:897-906.

9. Osborne ML, Pedula KL, O'Hollaren M, Ettinger KM, Stibolt T, Buist AS, et al. Assessing future need for acute care in adult asthmatics: the Profile of Asthma Risk Study: a prospective health maintenance organization-based study. Chest 2007; 132:1151-61.

10. Bloom CI, Palmer T, Feary J, Quint JK, Cullinan P. Exacerbation patterns in adults with asthma in England. A population-based study. Am J Respir Crit Care Med 2019;199: 446-453.

11. American Lung Association Asthma Clinical Research Centers, Peters SP, Anthonisen N, Castro M, Holbrook JT, Irvin $\mathrm{CG}$, et al. Randomized comparison of strategies for reducing treatment in mild persistent asthma. N Engl J Med 2007;356:2027-39.

12. Bateman ED, Reddel HK, O'Byrne PM, Barnes PJ, Zhong N, Keen $\mathrm{C}$, et al. As-needed budesonide-formoterol versus maintenance budesonide in mild asthma. $\mathrm{N}$ Engl $\mathrm{J}$ Med 2018;378:1877-87.

13. O'Byrne PM, FitzGerald JM, Bateman ED, Barnes PJ, Zhong $\mathrm{N}$, Keen $\mathrm{C}$, et al. Inhaled combined budesonide-formoterol as needed in mild asthma. N Engl J Med 2018;378:1865-76.

14. Ding B, Small M. Disease burden of mild asthma: finding from a cross-sectional real-world survey. Adv Ther 2017;34:110927.

15. Bleecker ER, FitzGerald JM, Chanez P, Papi A, Weinstein SF, Barker P, et al. Efficacy and safety of benralizumab for patients with severe asthma uncontrolled with high-dosage inhaled corticosteroids and long-acting $\beta$ 2-agonists (SIROCCO): a randomised, multicentre, placebo-controlled phase 3 trial. Lancet 2016;388:2115-27.

16. FitzGerald JM, Bleecker ER, Nair P, Korn S, Ohta K, Lommatzsch $\mathrm{M}$, et al. Benralizumab, an anti-interleukin-5 receptor $\alpha$ monoclonal antibody, as add-on treatment for patients with severe, uncontrolled, eosinophilic asthma (CALIMA): a randomised, double-blind, placebo-controlled phase 3 trial. Lancet 2016;388:2128-41.

17. Mcdonald VM, Hiles SA, Godbout K, Harvey ES, Marks GB, Hew M, et al. Treatable traits can be identified in a severe asthma registry and predict future exacerbations. Respirology 2019;24:27-47.

18. Taylor DR, Bateman ED, Boulet LP, Boushey HA, Busse WW, Casale TB, et al. A new perspective on concepts of asthma severity and control. Eur Respir J 2008;32:545-54.

19. Price DB, Rigazio A, Campbell JD, Bleecker ER, Corrigan CJ, Thomas $\mathrm{M}$, et al. Blood eosinophil count and prospective annual asthma disease burden: a UK cohort study. Lancet Respir Med 2015;3:849-58.

20. Bel EH. Clinical phenotypes of asthma. Curr Opin Pulm Med 2004; 10:44-50

21. Bloom CI, Nissen F, Douglas IJ, Smeeth L, Cullinan P, Quint JK. Exacerbation risk and characterization of the UK's asthma population from infants to old age. Thorax 2018;73;313-20.

22. FitzGerald JM, Barnes PJ, Chipps BE, Jenkins CR, O'Byrne PM, Pavord ID, et al. The burden of exacerbations in mild asthma: a systematic review. ERJ Open Res 2020;6:003592019.

23. Chipps BE, Haselkorn T, Paknis B, Ortiz B, Bleecker ER, Kianifard F, et al. More than a decade follow-up in patients with severe or difficult-to-treat asthma: The Epidemiology and 
Natural History of Asthma: Outcomes and Treatment Regimens (TENOR) II. J Allergy Clin Immunol 2018;141:1590-7.

24. Chung KF, Wenzel SE, Brozek JL, Bush A, Castro M, Sterk PJ, et al. International ERS/ATS guidelines on definition, evaluation and treatment of severe asthma. Eur Respir J 2014:43:34373.

25. Dales RE, Schweitzer I, Kerr P, Gougeon L, Rivington R, Draper J. Risk factors for recurrent emergency department vis- its for asthma. Thorax 1995;50:520-4.

26. Turner MO, Noertjojo K, Vedal S, Bai T, Crump S, Fitzgerald JM. Risk factors for near-fatal asthma. A case-control study in hospitalized patients with asthma. Am J Respir Crit Care Med 1998;157:1804-9.

27. Adams RJ, Smith BJ, Ruffin RE. Factors associated with hospital admissions and repeat emergency department visits for adults with asthma. Thorax 2000;55:566-73. 